\title{
Evaluation of the prospects of using kumquat in sauces technology
}

\author{
Oleg Kuzmin, Anna Bohomol, Anton Kuzmin \\ National University of Food Technologies, Kyiv, Ukraine
}

\begin{abstract}
The purpose of the work is to study the antioxidant properties of water-alcohol infusions from citrus fruits and to determine the feasibility of their application in the technology of sauces. The theoretical expected value of redox potential $(R P) E h_{\text {min }}$ is obtained for monitoring and has a value of $198,0 \mathrm{mV}$, the maximum value of $450,0 \mathrm{mV}$ (infusion of lemon pulp) is characteristic of plant water-alcohol infusions. The actual measured of $R P E h_{a c t}$ - from $114,0 \mathrm{mV}$ (control) to $298,0 \mathrm{mV}$ (infusion of pulp lemon). At the same time, the minimum value of the recovery energy $(R E)$ is $-84,0 \mathrm{mV}$ and is characteristic for control, and the greatest value of $205,0 \mathrm{mV}$ is the water-alcohol infusion from the kumquat peel. The $p H$ level for water-alcohol infusions ranges from 3,50 (lemon infusion pulp) to 5,90 (infusion of lemon peel), the extracts have an acidic medium. According to the results of research, wateralcohol infusions are grouped according to the antioxidant activity - according to $R E$ : extracts with average activity (from 100 to $200 \mathrm{mV}$ ) - mandarin, lemon, orange, grapefruit infusion; extract with high activity (from $200 \mathrm{mV}$ and above) - infusion of kumquat.
\end{abstract}

Corresponding author: kuzmin_ovl@ukr.net

E-mail: nataromano@ukr.net

DOI: $10.24263 /$ RES-2018-5

\section{Introduction}

The main directions of creating a new generation of sauces are: increase of antioxidant action, by blocking oxidative reactions [1-4]; reduction of the $\mathrm{pH}$ [1] of sauces, due to the obstruction of reproduction of microorganisms increase in terms of storage; improvement organoleptic parameters [1]. All this can be done by adding water-alcohol infusions to plant raw materials.

One of the promising directions for creating sauces is to increase their antioxidant action $[5,6]$ by introducing natural or identical natural compounds, active chemical compounds that prevent the oxidation of human cells and reduce the risk of developing various diseases, including those related to the action of chemical, physical, radiation, bacteriological and other factors of the environment.

Antioxidant activity [7] is manifested in the ability of compounds to neutralize the activity of free radicals $[8,5]$. Free radicals - products of oxidative processes in the body, occurring under the influence the environment $[7,9,10]$ (ionization, smoke, environmental pollution, the presence of toxins in food products).

Antioxidants make it possible to prolong the shelf life of food raw materials [11- 
14], semi-finished products and finished products, protecting them from damage caused by oxygenation of air, for example, scalding oils and fats or fatty components of food products, biologically valuable substances, and some natural dyes. Direct addition of antioxidants in the sauce leads to a slowdown in the oxidation of unsaturated fatty acids that are part of the lipids. In this case, the addition of antioxidants should not lead to the destruction of the structure and stratification of the sauce. It is very complex because of the fact that it involves a number of factors, stabilizing the effect of each of which manifests itself under certain conditions. Consequently, the technological process of production must be realized in such a way that the substances that are part of the sauce can be active and provide conditions for increasing the strength of the formation of complexes.

\section{Methods of research}

Redoxmetry - determination of antioxidant capacity of water-alcohol infusions of plant raw materials; $\mathrm{pH}$-metry; methods of determination of organoleptic parameters.

\section{Results and discussion}

Kumquat (fortunel, kinkan) is a group of plant species, which belongs to the family of root, which belongs to the genus citrus $[5,6,9,11,12]$. Fruits - small, medium-sized plum, golden-yellow, orange or fiery-orange; peel - smooth, fragrant, sweet-spicy; the pulp is juicy, with sour taste, close to mandarin, and citrus smell [13, 14]. In kumquat there is a significant amount of flavonoids [8,9], polyphenols $[6,10$, 13], carotenoids [14], luteins and tannins, which are known antioxidants $[6,7,8,9,10]$.

The comparative characteristic of the food and energy value of kumquat in relation to orange, mandarin is presented in the Table 1.

Kumquat is $33,8 \%$ more caloric in relation to orange and $25,4 \%$ in relation to mandarin. In relation to mandarin and orange, kumquat has a higher content of fats, carbohydrates, minerals that perform plastic and protective functions, and also affect the metabolism of humans. Significantly higher vitamin content in kumquat prevents the development of diseases and pathologies, as well as improves the general condition

of a person. The exception is vitamins $\mathrm{B}_{1}, \mathrm{~B}_{5}, \mathrm{~B}_{6}$, the content of which in kumquat is less than in oranges and mandarins, therefore the use of kumquat in recipes is possible with incomplete replacement for orange or mandarin. 
Resource and Energy Saving Technologies of Production and Packing of Food Products as the Main Fundamentals of Their Competitiveness: Proceedings of the 7th International Specialized Scientific and Practical Conference, September 13, 2018. Kyiv, Ukraine

Table 1

Comparative characteristics of the food and energy value of kumquat in relation to orange, mandarin

\begin{tabular}{|l|c|c|c|c|c|}
\hline \multicolumn{1}{|c|}{ Nutrient } & $\begin{array}{c}\text { Quantity } \\
\text { in 100 g of } \\
\text { orange }\end{array}$ & $\begin{array}{c}\text { Quantity in } \\
100 \mathrm{~g} \text { of } \\
\text { mandarin }\end{array}$ & $\begin{array}{c}\text { Quantity in } \\
100 \mathrm{~g} \text { of } \\
\text { kumquat }\end{array}$ & $\begin{array}{c}\text { Kumquat/ } \\
\text { orange, }+ \text {-/ } \\
\%\end{array}$ & $\begin{array}{c}\text { Kumquat/ } \\
\text { mandarin, } \\
+/-, \%\end{array}$ \\
\hline Proteins, g & 0,94 & 0,81 & 1,88 & 50,0 & 56,9 \\
\hline Fat, g & 0,12 & 0,10 & 0,86 & 86,0 & 88,4 \\
\hline Carbohydrates, g: & 11,75 & 8,70 & 15,90 & 26,1 & 45,3 \\
- food fibers; & 2,40 & 1,20 & 6,50 & 63,1 & 81,5 \\
- monosaccharides & 9,35 & 7,50 & 9,36 & 0,1 & 19,9 \\
\hline Potassium, mg & 181,0 & 37,0 & 186,0 & 2,7 & 80,1 \\
\hline Calcium, mg & 40,0 & 0,0 & 62,0 & 35,5 & 100,0 \\
\hline Magnesium, mg & 10,0 & 12,0 & 20,0 & 50,0 & 40,0 \\
\hline Phosphorus, mg & 14,0 & 20,0 & 19,0 & 26,3 & $-5,3$ \\
\hline Sodium, mg & 0,0 & 2,0 & 10,0 & 100,0 & 80,0 \\
\hline Copper, mg & 0,045 & 0,000 & 0,095 & 52,6 & 100,0 \\
\hline Iron, mg & 0,10 & 0,15 & 0,86 & 88,4 & 82,6 \\
\hline Zinc, mg & 0,07 & 0,00 & 0,17 & 58,8 & 100,0 \\
\hline Vitamin C, mg & 53,2 & 26,7 & 43,9 & $-21,2$ & 39,2 \\
\hline Vitamin B, $\mathrm{mg}$ & 0,087 & 0,058 & 0,037 & $-135,1$ & $-56,8$ \\
\hline Vitamin B, mg & 0,040 & 0,036 & 0,090 & 55,6 & 60,0 \\
\hline Vitamin B, $\mathrm{mg}$ & 0,282 & 0,376 & 0,429 & 34,3 & 12,4 \\
\hline Vitamin B, $\mathrm{mg}$ & 0,250 & 0,216 & 0,208 & $-20,2$ & $-3,8$ \\
\hline Vitamin B, $\mathrm{mg}$ & 0,060 & 0,078 & 0,036 & $-66,7$ & $-116,7$ \\
\hline Vitamin A, me & 225,0 & 0,0 & 290,0 & 22,4 & 100,0 \\
\hline Vitamin E, mg & 0,018 & 0,000 & 0,015 & $-20,0$ & 100,0 \\
\hline Energy value, kcal & 47,0 & 53,0 & 71,0 & 33,8 & 25,4 \\
\hline
\end{tabular}

Water-alcohol infusions were obtained by extraction of a water-alcohol blend (in volume of $100 \mathrm{ml}$ ) with a volume fraction of ethyl alcohol rectified $40 \%$ of plant material (size $\approx 3 \times 3 \mathrm{~mm}$, weighing $4 \mathrm{~g}$ ) with double tension (maceration) at the usual temperature, which consists of the following operations: raw material acceptance and weighing; sorting of raw materials and waste disposal; weighing of waste; shredding of raw materials; preparation of a water-alcohol mixture of required strength; loading of raw material into an emergency capacity; gulf of raw materials with a water-alcohol mixture; insertion of raw materials with a water-alcohol mixture at daily stirring for 5 days depending on the type of raw material; the pumping and pumping of the first draft into the collections for storing and measuring the volume of the received infusion; second gulf of raw materials with a water-alcohol mixture; reintroduction of raw materials with a water-alcohol mixture at daily stirring for 5 days; discharge, pumping and measurement of the volume received by the infusion of the first and second drains; mixing of infusions of the first and second drains; unloading of consumed raw material from an emergency capacity; evaporating the alcohol that was left in the spent raw 
material. In the process of extraction, a diffusion phenomenon is used, based on the concentration alignment between the solvent (extractant) and the solution of substances contained in the plant cell.

The indicator of active acidity $p H$ was measured on the $p H$-meter pH150MI with a combined glass electrode ESK-10603. $R P$ was measured on the $p H$-meter $\mathrm{pH} 150 \mathrm{MI}$ with combined redox metric platinum electrode ERP-105.

For not activated inorganic solutions in steady state, there is a right formula that relates the rate of active acidity of $p H$ and $R P[1]$ :

$$
E h_{\text {min }}=660-60 \cdot p H, \mathrm{mV}
$$

where $E h_{\min }$ - minimal theoretically expected meaning of the $R P$; $p H-$ active acidity of tested solution.

Acquired meanings of $E h_{\min }$ were compared with the actual measurements of $E h_{a c t}$ of solution. The shift of $R P$ to the side of the recovered meanings $-R E$ was determined by the formula:

$$
R E=E h_{\min }-E h_{a c t}, \mathrm{mV}
$$

where $R E$ - the shift of $R P$ to the side of recovered meanings (resilence);

$E h_{\text {min }}$ - minimal theoretically expected meaning of $R P$;

$E h_{a c t}$-actual measured $R P$.

For the study samples of citrus fruits were selected: kumquat, mandarin, orange, lemon, grapefruit, which were evaluated for organoleptic and physico-chemical parameters (table 2).

According to the results of research, water-alcohol infusions are grouped according to the antioxidant activity - according to $R E$ : extracts with average activity (from 100 to $200 \mathrm{mV}$ ) - mandarin, lemon, orange, grapefruit infusion; extract with high activity (from $200 \mathrm{mV}$ and above) - infusion of kumquat.

In fig. 1-2 graphic dependence of physicochemical and organoleptic parameters of water-alcohol infusions from citrus is presented. 
Resource and Energy Saving Technologies of Production and Packing of Food Products as the Main Fundamentals of Their Competitiveness: Proceedings of the 7th International Specialized Scientific and Practical Conference, September 13, 2018. Kyiv, Ukraine

Table 2

Indicators of $R P$ of water-alcohol infusions from citrus at $t=20^{\circ} \mathrm{C}$

\begin{tabular}{|l|c|c|c|c|c|}
\hline \multicolumn{1}{|c|}{ Raw } & Org, points & $p H$ & $E h_{\min }, \mathrm{mV}$ & $E h_{\text {act }}, \mathrm{mV}$ & $R E, \mathrm{mV}$ \\
\hline Water-alcohol mixture 40\% v. & 9,680 & 7,70 & 198,0 & 114,0 & 84,0 \\
\hline Infusion of grapefruit (peel) & 9,651 & 5,53 & 328,2 & 202,0 & 126,2 \\
\hline Infusion of lemon (peel) & 9,659 & 5,90 & 306,0 & 169,0 & 137,0 \\
\hline Infusion of mandarin (peel) & 9,590 & 5,49 & 330,6 & 190,0 & 140,6 \\
\hline Infusion of grapefruit (pulp) & 9,573 & 4,58 & 385,2 & 234,0 & 151,2 \\
\hline Infusion of lemon (pulp) & 9,620 & 3,50 & 450,0 & 298,0 & 152,0 \\
\hline Infusion of orange (peel) & 9,597 & 4,90 & 366,0 & 199,0 & 167,0 \\
\hline Infusion of orange (pulp) & 9,583 & 4,72 & 376,8 & 203,0 & 173,8 \\
\hline Infusion of mandarin (pulp) & 9,540 & 4,63 & 382,2 & 196,0 & 186,2 \\
\hline Infusion of kumquat (pulp) & 9,645 & 3,87 & 427,8 & 224,0 & 203,8 \\
\hline Infusion kumquat (peel) & 9,656 & 5,00 & 360,0 & 155,0 & 205,0 \\
\hline \multicolumn{1}{|c|}{ min } & 9,540 & 3,50 & 198,0 & 114,0 & 84,0 \\
\hline max & 9,680 & 7,70 & 450,0 & 298,0 & 205,0 \\
\hline
\end{tabular}

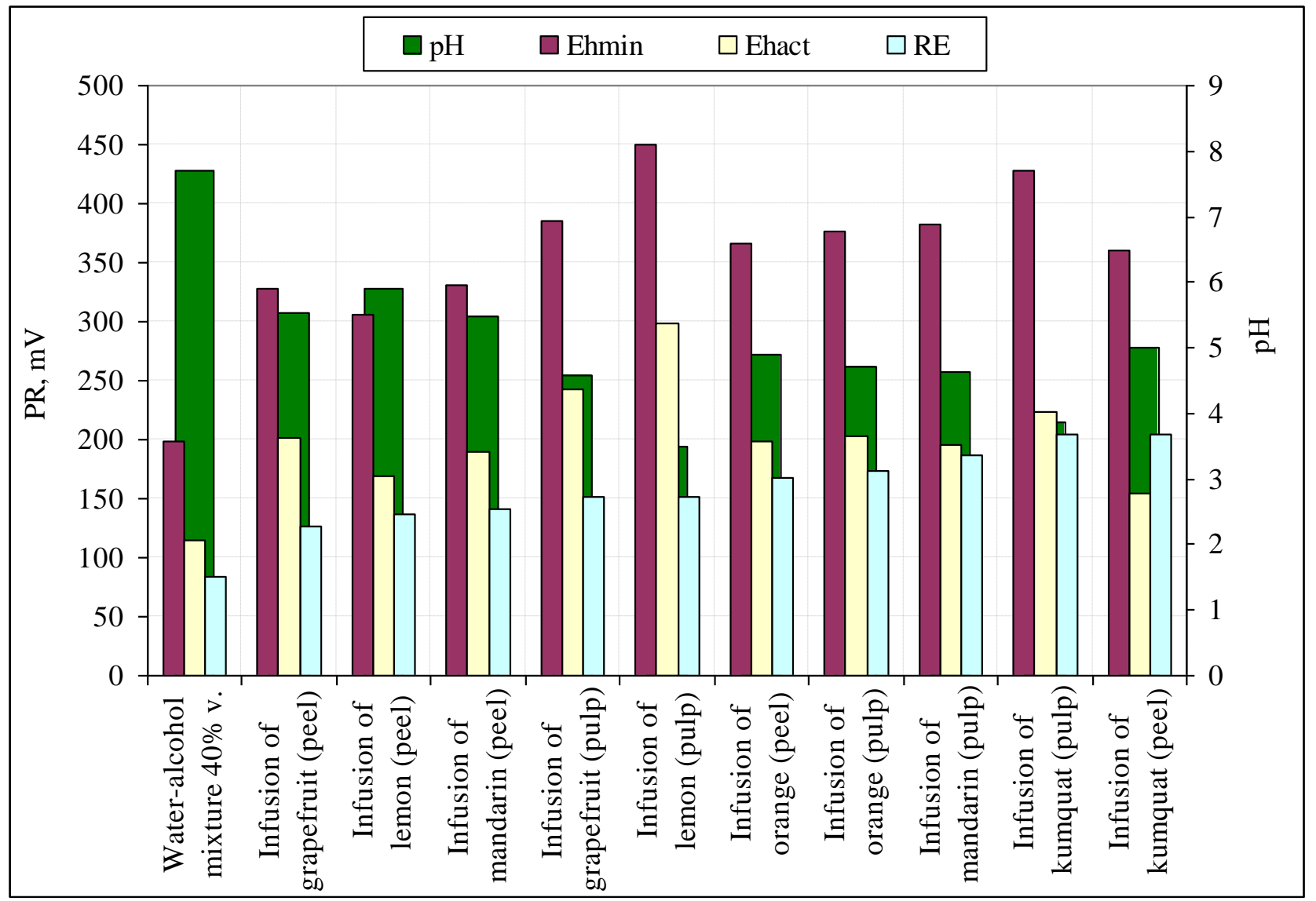

Figure 1. Graphic dependence of physicochemical indices of water-alcohol infusions from citrus 
Resource and Energy Saving Technologies of Production and Packing of Food Products as the Main Fundamentals of Their Competitiveness: Proceedings of the 7th International Specialized Scientific and Practical Conference, September 13, 2018. Kyiv, Ukraine

Adding vegetable alcoholic and alcoholic infusions from citrus to sauces regulates their acidity by reducing the $\mathrm{pH}$ that prevents the reproduction of microorganisms and enrich them with vitamins and trace elements.

It has been experimentally established that the largest $R P$ are infusions from a kumquat. It is expedient to use them in the technology of production of red sauces, for example, red orange sauce, in order to increase antioxidant properties.

The recipe composition of the improved red orange sauce is shown in Table. 3

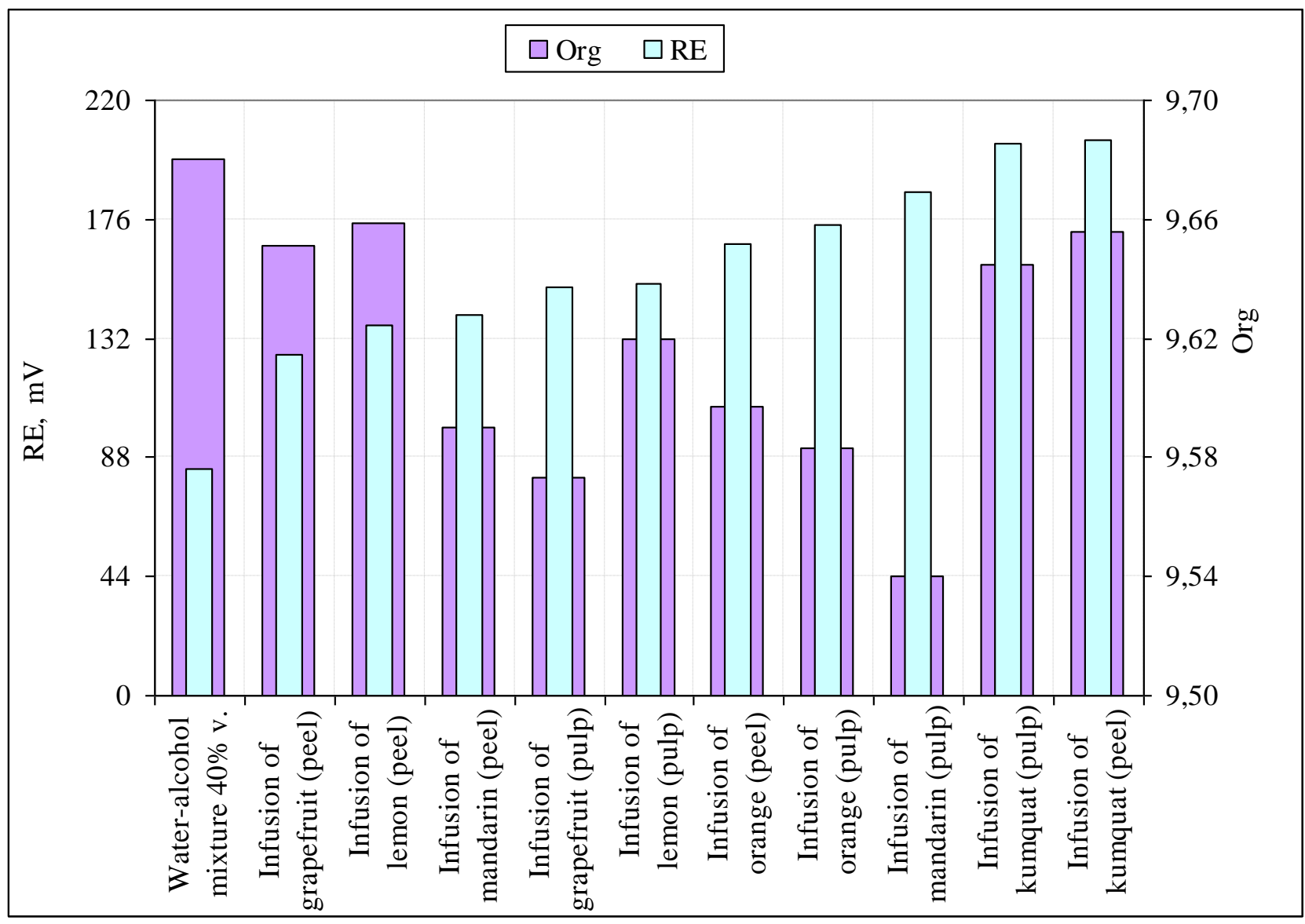

Figure 2. Graphic dependence of organoleptic parameters and energy of restoration of water-alcohol infusions from citrus 
Resource and Energy Saving Technologies of Production and Packing of Food Products as the Main Fundamentals of Their Competitiveness: Proceedings of the 7th International Specialized Scientific and Practical Conference, September 13, 2018. Kyiv, Ukraine

Table 3

Composition of the recipes of the red main sauce of oranges

\begin{tabular}{|l|c|}
\hline \multicolumn{1}{|c|}{ Raw } & Content, \% \\
\hline Red turnip sauce №824 or №825 & $64,1-64,5$ \\
\hline Orange (pulp) & $8,01-8,05$ \\
\hline Oranges (peel) & $2,95-2,85$ \\
\hline Kumquat (pulp) & $8,01-8,05$ \\
\hline Kumquat (peel) & $2,91-2,85$ \\
\hline Wine red & $4,37-4,05$ \\
\hline Infusion of kumquat & $4,45-4,05$ \\
\hline Butter & $5,2-5,6$ \\
\hline
\end{tabular}

\section{Conclusions}

The feasibility of using kumquat in sauces is scientifically substantiated. The antioxidant activity of citrus-water alcoholic infusions has been investigated and the rational ratios of the recipe composition of red sauce have been developed.

\section{References}

1. Kuzmin O., Kovalchuk Y., Velychko V., Romanchenko N. (2016), Improvement technologies of water-alcohol infusions for the production of syrups, Ukrainian Journal of Food Science, vol. 4, issue 2, pp. 258-275.

2. Dietrich I., Kuzmin O., Mikhailenko V. (2017), Comprehensive evaluation of the hot sweet soufflé dessert quality, Ukrainian Journal of Food Science, vol. 5, issue 1, pp. 92-102.

3. Kuzmin O., Suikov S., Koretska I., Matiyashchuk O., Poliovyk V. (2017), Identification of equilibrium state of hydroxyl protons in vodkas by ${ }^{1} \mathrm{H}$ NMR spectroscopy, Ukrainian Food Journal, vol. 6, issue 2, pp. 314-336.

4. Kuzmin O., Zubkova V., Shendrik T., Korenets Y., Kuzmin A., Bilenkyi P. (2018), Internal mechanisms for establishment of the equilibrium state of water-alcohol mixtures in vodka technology, Ukrainian Food Journal, vol. 7, issue 4, pp. 655-670.

5. Jia-jing Guo, Zhi-peng Gao, Jin-lan Xia, Mark A. Ritenour, Yang Shan (2018), Comparative analysis of chemical composition, antimicrobial and antioxidant activity of citrus essential oils from the main cultivated varieties in China, $L W T$, vol. 97, pp. 825-839.

6. Deena Ramful, Evelyne Tarnus, Okezie I. Aruoma, Emmanuel Bourdon, Theeshan Bahorun (2011), Polyphenol composition, vitamin C content and antioxidant capacity of Mauritian citrus fruit pulps, Food Research International, vol. 44, issue 7, pp. 2088-2099.

7. Satoru Kondo, Rie Katayama, Koji Uchino (2005), Antioxidant activity in meiwa 
kumquat as affected by environmental and growing factors, Environmental and Experimental Botany, vol. 54, issue 1, pp. 60-68.

8. Shyi-Neng Lou, Yi-Chun Lai, Jia-De Huang, Chi-Tang Ho, Yung-Chung Chang (2015), Drying effect on flavonoid composition and antioxidant activity of immature kumquat, Food Chemistry, vol. 171, pp. 356-363.

9. Davide Barreca, Ersilia Bellocco, Corrado Caristi, Ugo Leuzzi, Giuseppe Gattuso (2011), Kumquat (Fortunella japonica Swingle) juice: Flavonoid distribution and antioxidant properties, Food Research International, vol. 44, issue 7, pp. 2190-2197.

10. Shyi-Neng Lou, Yi-Chun Lai, Ya-Siou Hsu, Chi-Tang Ho (2016), Phenolic content, antioxidant activity and effective compounds of kumquat extracted by different solvents, Food Chemistry, vol. 197, part A, pp. 1-6.

11. Amedeo Palma, Salvatore D'Aquino (2018), Kumquat - Fortunella japonica, Exotic Fruits, pp. 271-278.

12. Yumin Liu, Yu Liu, Yamin Liu, Hongding Liu, Yanshuang Shang (2018), Evaluating effects of ellagic acid on the quality of kumquat fruits during storage, Scientia Horticulturae, vol. 227, pp. 244-254.

13. Shyi-Neng Lou, Chi-Tang Ho (2017), Phenolic compounds and biological activities of small-size citrus: Kumquat and calamondin, Journal of Food and Drug Analysis, vol. 25, issue 1, pp. 162-175.

14. Attila Agócs, Veronika Nagy, Zoltán Szabó, László Márk, József Deli (2007), Comparative study on the carotenoid composition of the peel and the pulp of different citrus species, Innovative Food Science \& Emerging Technologies, Volume 8, Issue 3, pp. 390-394. 